\title{
Cisapride Stimulates Small Intestinal Motility and Relieves Constipation in Myelopathy due to Cervical Spinal Stenosis: Case Report
}

\author{
P. M. Hellström, MD, PhD, A. Aly, MD, PhD, C. Johansson, MD, PhD \\ Department of Medicine, Gastroenterology Unit, Karolinska Hospital, Stockholm, \\ Sweden.
}

\section{Summary}

A patient with progressive spinal stenosis, paraplegia, chronic pain syndrome and simultaneous severe chronic constipation is described. Treatment with cisapride $10 \mathrm{mg}, 4$ times daily improved her condition, and this was associated with improved small intestinal motility during a 12-hour examination using a computer aided system.

Key words: Cisapride; Cervical spinal stenosis; Myelopathy; Constipation; Gastrointestinal motility

Cisapride is a novel prokinetic drug. It enhances antroduodenal co-ordination (Schuurkes et al., 1983), and shortens intestinal transit time in normal human subjects (Van Wyk et al., 1985; Edwards et al., 1987) and in patients with chronic intestinal pseudo-obstruction (Camilleri et al., 1986). Cisapride also stimulates colonic motility in healthy and constipated subjects (Altaparmakov, 1985). Gastroenterologists often encounter severe constipation in patients with spinal injury who develop abdominal discomfort and pain. A case of a patient with spinal stenosis, investigated in detail because of severe constipation and later treated with cisapride, is reported.

\section{Case report}

A 50-year-old woman with an 8-year history of progressive stenosis of the cervical spine developed intractable constipation, frequent vomiting and malnutrition. Due to the development of neurological symptoms, decompressive laminectomies and anterior fusion of spinal vertebrae according to Cloward had been carried out previously. At admission she had paraplegia, partial paresis of the arms and hands, and decreased sensation in the trunk, arms, hands, legs and feet. In addition, she had cervical rhizopathy with disabling radiating pains that were only partially relieved by electrical stimulation of the dorsal columns of the cervical and lumbar spinal cord through electrodes implanted 4 years earlier. Neurogenic urinary bladder dysfunction without progression had been present for 3 years. 
Gastrointestinal symptoms had started 1 year before admission and were considered secondary to spinal injury; she was constantly nauseated with vomiting up to 25 times daily, $15 \mathrm{~kg}$ body weight decrease and severe chronic constipation with abdominal pain and no spontaneous defecations. Clinical examination, gastroscopy and sigmoideoscopy were normal. A barium enema demonstrated a slightly dilated colon without strictures and impacted faeces along its entire length. Routine laboratory investigations were all normal. Interdigestive motility of the descending duodenum was investigated over a 12-hour period with a computer aided system using two tip transducers $5 \mathrm{~cm}$ apart. Migrating motility complexes (MMCs) were identified according to the criteria described by Vantrappen $e t$ al. (1977): appearance of the activity front as uninterrupted bursts of pressure waves with a frequency of 11-12 per minute, aboral migration of the activity front, and a period of quiescence after the activity front. Recordings showed occurrence of three MMCs with aborally propagated activity fronts at a mean velocity of $8.3 \mathrm{~cm} / \mathrm{min}$. The intervals between the activity fronts were 162 to 282 minutes compared to 60 to 150 minutes in normal females at a similar age.

Vomiting was recorded as repeated rapid pressure increases exceeding $200 \mathrm{~mm} \mathrm{Hg}$ and rapid retrograde propagation of about $5 \mathrm{~cm}$ per second. Vomiting occurred 15 times during
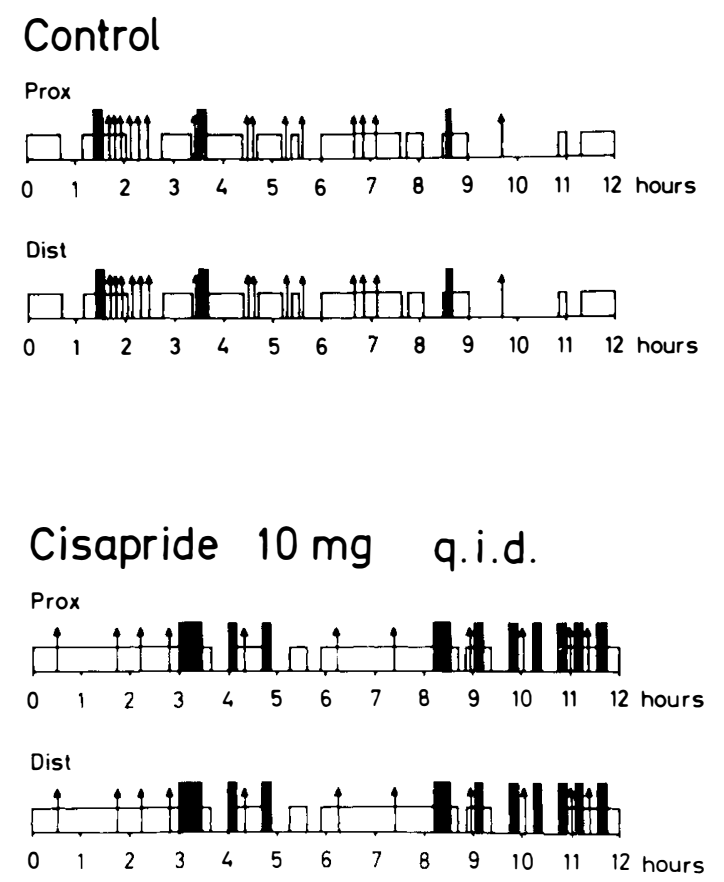

Figure Schematic presentation of the recurring migrating motility complexes of the descending duodenum during a 12-hour registration period under control conditions (upper panel) and after 6 weeks of treatment with cisapride $10 \mathrm{mg}, 4$ times daily (lower panel). Prox = proximal tip pressure transducer, Dist $=$ distal tip pressure transducer, located $5 \mathrm{~cm}$ apart. $L$ indicates an activity front, $\square$ indicates irregular contractions and $\uparrow$ indicates vomiting.

the control registration (Figure). Whole gut transit time was 4.5 days studied by means of continuous administration of radiopaque plastic rings (diameter $3 \mathrm{~mm}$, thickness $2 \mathrm{~mm}$ ) during 6 days with abdominal X-ray on the seventh day and calculation of the remaining markers (normal: mean \pm SD $2 \cdot 5 \pm 1 \cdot 2$, range $1 \cdot 3-5 \cdot 3$ ). The diagnosis was considered as chronic constipation on the basis of progressive spinal injury.

Medical treatment with lactulose led to one or two bowel movements during the week, but frequent enemas still had to be used. Additional treatment with metoclopramide had no effect on bowel habit or nausea. Six weeks after the onset of treatment with cisapride 
$10 \mathrm{mg}, 4$ times daily a steady state plasma concentration of $13.5 \mathrm{ng} / \mathrm{ml}$ was achieved. A further 12-hour recording of interdigestive motility in the descending duodenum was made during this treatment and it showed frequent irregular contractions and 10 MMCs. The activity fronts occurred at intervals of 22 to 231 minutes with an aboral propagation at a mean velocity of $8.0 \mathrm{~cm}$ per minute. During the recording 12 vomitings were recorded (Figure). Whole gut transit time simultaneously decreased to $2 \cdot 6$ days. During 19 months of continuous treatment constipation was reduced and bowel habits improved with daily spontaneous defecation. No side-effects were observed. However, no definite relief of nausea or pain was achieved. Therefore, treatment with domperidone $10 \mathrm{mg}, 4$ times daily was started, and the vomiting was reduced from about 25 to about 15 times a day.

\section{Discussion}

Cisapride was shown to stimulate motility of the duodenum and relieve severe constipation in a patient with spinal injury. No definite effects were observed regarding nausea or pain. One explanation for the prokinetic action of cisapride may be that it increases the contraction force in intestinal smooth muscle as shown in dogs (Schuurkes et al., 1983; Lee et al., 1984; Schemann and Ehrlein, 1984). In fasting man, cisapride induces a propagative phase 2-like jejunal motor activity (Stacher et al., 1986; Stacher et al., 1987). Others, using electromyographic techniques in man, have found a phase 3-like activity which differs from regular phase 3 by the absence of spikes on some slow waves and absence of phase-locking between different electrodes (Coremans et al., 1985). Furthermore, cisapride has been shown to reduce intestinal transit time in normal humans (Van Wyk et al., 1985; Edwards et al., 1987) as well as in chronic intestinal pseudo-obstruction (Camilleri et al., 1986). Such results are in agreement with the present findings.

Although the plasma concentrations in our patient were lower than therapeutic plasma levels reported in other studies (i.e. $20-40 \mathrm{ng} / \mathrm{ml}$ ), there may be individual variation in sensitivity for the drug and gastrointestinal motility might be regulated in an abnormal way in spinal injury making it more sensitive to stimulation by cisapride. As cisapride relieved constipation in our patient, we assume that stimulated motility and emptying of the small intestine into the colon may be of importance for the ensuing bowel movements.

\section{Acknowledgements}

The investigation was supported by Swedish Medical Research Council (no. 7916), Magnus Bergvall's foundation and Wiberg's foundation.

\section{References}

Altaparmakov I 1985 Non-cholinergic stimulation of contractile activity of human colon by a novel gastrointestinal prokinetik cisapride. Naunyn-Schmiedeberg's Archives of Pharmacology 330 (Supplement):R77.

Camilleri M, Brown ML, Malagelada J-R 1986 Impaired transit of chyme in chronic intestinal pseudoobstruction. Correction by cisapride. Gastroenterology 91:619--626.

Coremans G, Chaussade S, Janssens J, Vantrappen G, Ceccatelli P 1985 Stimulation of propulsive motility patterns by cisapride in the upper gut in man. Digestive Diseases and Sciences 30:765.

EdWARDS CA, Holden S, BROWN C, READ NW 1987 Effect of cisapride on the gastrointestinal transit of a solid meal in normal subjects. Gut 28:13-16.

LEE KY, Chey WY, You CH, ShaH AN, Hamilton D 1984 Effect of cisapride on the motility of gut in dogs and colonic transit time in dogs and humans. Gastroenterology 86:1157. 
SCHEMANN M, EhrLein H 1984 Cisapride stimulates peristaltic activity of the canine jejunum during the digestive period. Gut 25:1310A.

SChuURkes JAJ, Verlinden M, AkKermans LMA, Van Nueten JM 1983 Stimulating effects of R 51619 on antroduodenal motility in the conscious dog. Gastroenterologic Clinique et Biologique 7:704.

Stacher G, Steinringer H, Schneider C, Winklehner S, Mittelbach G, Gaupmann G 1986 Effects of cisapride on jejunal motor activity in fasting healthy humans. Gastroenterology 90:1210 1216.

Stacher G, Gaupmann G, Mittelbach G, Schneider C, Steinringer H, Langer B 1987 Effects of oral cisapride on interdigestive jejunal motor activity, psychomotor function, and side-effect profile in healthy man. Digestive Diseases and Sciences 32:1223-1230.

Vantrappen G, Janssens J, Hellemans J, Ghoos Y 1977 The interdigestive motor complex of normal subjects and patients with bacterial overgrowth of the small intestine. Fournal of Clinical Investigation 59:1158-1166.

VAN WYK M, SOMmers DE K, STEYN AGW 1985 Evaluation of gastro-intestinal motility using the hydrogen breath test. British fournal of Clinical Pharmacology 20:479-481. 